\title{
Postsecondary Students with Specific Learning Disabilities and with Attention Deficit Hyperactivity Disorder Should Not be Considered as a Unified Group For Research or Practice
}

\author{
Jillian Budd $^{1,2}$, Catherine S. Fichten ${ }^{1,2,3,4}$, Mary Jorgensen ${ }^{1}$, Alice Havel ${ }^{1,3}$, Tara Flanagan ${ }^{2}$ \\ ${ }^{1}$ Adaptech Research Network, Montreal, Québec, Canada \\ ${ }^{2}$ McGill University, Montreal, Québec, Canada \\ ${ }^{3}$ Dawson College - Montreal, Québec, Canada \\ ${ }^{4}$ Jewish General Hospital - Montreal, Québec, Canada \\ Correspondence: Jillian Budd, Adaptech Research Network, 3040 Sherbrooke St. West, Montreal, Québec, H3Z 1A4, \\ Canada
}

Received: December 17, 2015 Accepted: January 4, 2016 Online Published: February 17, 2016

doi:10.11114/jets.v4i4.1255

URL: http://dx.doi.org/10.11114/jets.v4i4.1255

\begin{abstract}
Objective: To examine similarities and differences among college/university students with ADHD, LD, and comorbid ADHD and LD on variables related to academic performance.

Method: Students who self-reported ADHD $(n=42)$, LD $(n=72)$, or comorbid ADHD and LD $(n=42)$, completed an online questionnaire which evaluated grades, parental education, course and social self-efficacy, and personal and school related obstacles and facilitators.

Results: Students with ADHD (with or without comorbidity) reported the worst grades, personal situations (e.g., study habits, personal motivation), and course-related self-efficacy (e.g., time management, keeping up-to-date with school work). The single exception was that students with ADHD had more confidence in understanding textbooks than students with LD. Comorbid ADHD and LD sometimes led to worse outcomes than LD or ADHD alone.

Conclusion: The common practice of combining all three groups, "LD and/or ADHD", should be avoided. Suggestions are made about what could be done to help students with ADHD.
\end{abstract}

Keywords: postsecondary, college, university, learning disabilities, attention deficit hyperactivity disorder, executive functioning, comorbidity, self-efficacy

\section{Introduction}

Large numbers of students with specific learning disabilities (SLD) and with attention deficit-hyperactivity disorder (ADHD) are attending colleges and universities. In 2008-2009, among students with disabilities in the United States, 31\% had LD and 18\% had ADHD (Raue \& Lewis, 2011). Since ADHD and LD often co-occur (DuPaul, Gormley, \& Laracy, 2013) many students fall into both groups. Due to the high comorbidity and shared characteristics of the disorders, research and interventions often classify them as one group "LD and/or ADHD" (e.g., Parker \& Banerjee, 2007). We examined aspects related to academic performance among postsecondary students with LD, ADHD, and comorbid ADHD and LD to determine specific group differences that may influence postsecondary intervention and research practices.

\subsection{Postsecondary Students with ADHD}

While the exact number of students with ADHD attending postsecondary institutions is unknown, the American College Health Association (2013) sampled over 34,000 Canadian postsecondary students, of which 4.6\% indicated they have ADHD. The disorder is characterized as a persistent pattern of inattention and/or hyperactivity-impulsivity which interferes with an individual's functioning (American Psychiatric Association, 2013). Additionally, individuals with ADHD often experience deficits in executive functioning (e.g., time management, organization) (see Tarver, Daley, \& Sayal, 2014). 
Students with ADHD generally have difficulty in postsecondary education; they tend to have worse grades, are more likely to be on academic probation, and are less likely to graduate than their peers without disabilities (Advokat, Lane, \& Luo, 2011; Weyandt et al., 2013). Additionally, more students with ADHD report forgetting, having to read material over and over, performing poorly on timed tests, taking longer to complete assignments, difficulty sustaining attention, failing to finish schoolwork, difficulty listening, and difficulty organizing tasks than students without disabilities (Lewandowski, Lovett, Codding, \& Gordon, 2008).

\subsection{Postsecondary Students with LD}

Learning disabilities are lifelong neurodevelopmental disorders that result in difficulties acquiring academic skills such as reading, writing, and mathematical reasoning, despite having average to above average cognitive abilities (American Psychiatric Association, 2013; Harrison \& Holmes, 2012). Individuals with LD comprise close to half of all students with disabilities in colleges and universities (McCloy \& DeClou, 2013; National Center for Education Statistics, 2011). This number is undoubtedly higher when we consider students who are not yet aware of their LD (Harrison, Larochette, \& Nichols, 2007) and those who choose not to disclose it (Rath \& Royer, 2002).

Students with LD also have difficulty in postsecondary education as they tend to have lower grades and graduation rates than their peers without disabilities (Jorgensen, Fichten, \& Havel, 2009; Wagner, Newman, Cameto, Garza, \& Levine, 2005), as well as academic self-efficacy (Hen \& Goroshit, 2014; Lackaye \& Margalit, 2006), a variable that has been related to postsecondary grades (Butler, 2011; Richardson, Abraham, \& Bond, 2012). These students may have difficulty meeting the academic demands of college or university (Gregg, 2007) including with studying, spelling, note-taking, organizing essays, and expressing their ideas in writing (Mortimore \& Crozier, 2006).

\section{$1.3 \mathrm{LD}$ and/or $A D H D$}

Current trends in research and practice often describes students with LD and with ADHD as one unified group without considering comorbidity (e.g., LD and/or ADHD) (e.g., Parker \& Banerjee, 2007) or classifies ADHD as a type of LD (Bizier, Till, \& Nicholls, 2014). There are several reasons for this including: 1) high comorbidity rates (cf. 45\%, DuPaul et al., 2013), 2) similar functional outcomes such as lower grades and higher rates of college drop-out (Advokat et al., 2011; Barkley, Fischer, Smallish, \& Fletcher, 2006; Kent et al., 2011; Prevatt \& Young, 2014), 3) common cognitive processing impairments including processing speed and working memory (see Katz, Brown, Roth, \& Beers, 2011), and 4) common precursors of postsecondary success such as motivation and attitude (Reaser, Prevatt, Petscher, \& Proctor, 2007).

Despite these similarities, unique differences between LD and ADHD have been found. For instance, Bental and Tirosh (2007) found that reading performance in LD was associated with phonological awareness and verbal working memory however, it was associated with rapid naming and executive functioning in those with ADHD. Additionally, individuals with ADHD were significantly more impaired in objective measures of planning than individuals with LD and controls (Marzocchi et al., 2008). Furthermore, postsecondary students with ADHD reported significantly worse time management, concentration, ability to select main ideas and use study aids than students with LD (Reaser et al., 2007).

\subsection{Present Study}

Since using a single category (LD and/or ADHD) may mask important group differences, we compared and contrasted aspects related to academic performance among postsecondary students with LD, ADHD, and comorbid LD and ADHD on self-reported grades, academic self-efficacy as well as obstacles and facilitators to academic success. The goal of the present study was to determine whether the groups should be combined in research and to inform service providers about specific group needs and differences. Thus, we sought to answer the following questions:

1. Do the three groups differ on demographic characteristics, self-reported grades, self-efficacy, or obstacles and facilitators to academic success? Given the reported similarities among the groups in the literature, we compared the groups on demographic and student-related information (e.g., age, gender, field of study, grades). We also compared the groups' confidence to successfully perform academic-related tasks. While research has shown that students with LD tend to have lower academic self-efficacy than their non-disabled peers, this variable has not yet been examined in postsecondary students with ADHD who do not have any comorbidity. Furthermore, to determine possible unique group experiences, we evaluated whether specific personal or school-related situations made each group's studies easier or harder.

2. What variables are related to higher self-reported grades and to other aspects related to academic success? Previous research shows that facilitating personal situations and school experiences are related to college grades (Jorgensen et al., 2009). Additionally, higher parental education (DeDonno \& Fagan, 2013) and postsecondary grades (Butler, 2011) are related to strong academic self-efficacy beliefs. Thus, we explored the relationships among these 
variables for both students with LD and those with ADHD and examined whether these relationships differed between the groups.

\section{Method}

\subsection{Procedure}

This investigation was part of a larger study that sought to help identify facilitating factors and barriers to students with disabilities pursuing college or university education in Canada (Fichten et al., 2014). In 2010, we recruited 611 current students with disabilities who were enrolled in a diploma or degree program in a Canadian postsecondary institution. The participants in the current study $(n=156)$ are a subsample of the original investigation as we sought to examine the experiences of those who have either LD, ADHD, or comorbid LD and ADHD. The remainder of participants $(n=455)$ did not meet our inclusion criteria as the participants did not self-report LD or ADHD or they reported other comorbidities (e.g., chronic medical/health impairment, mental health related impairment).

We recruited participants by (1) emailing announcements to discussion lists focused on Canadian postsecondary education and to project partners (mainly student and campus disability service provider groups) and (2) emailing invitations to students with disabilities in higher education who had previously participated in one of our studies. Potential participants were directed to a webpage which included a description of the study and a consent form (approved by Dawson College's Research Ethics Board). Participants were informed that the online questionnaire would take approximately 20 minutes to complete and that they would receive a $\$ 20$ honorarium. Participants pressed the "continue" button which brought them to the universally designed, accessible online survey. Thus, participants were able to access the questionnaire in ways that best suit their needs. For example, students with reading difficulties could use text-to-speech software to listen to the questions being read aloud. Additionally, students with difficulties with impulsivity could go back and forth between pages.

Four weeks after participants completed the initial survey, those who gave permission to be contacted again $(n=533)$ were asked to complete the questionnaire a second time allowing us to calculate test-retest reliability. In total, $44 \%(n=$ 236) completed the retest and high test-retest reliability was established as most measures had positive correlations of 8 or above. The same pattern of results was found for those in the current sample of which $35 \%(n=46)$ of those who agreed to be contacted again $(n=133)$ completed the retest.

\subsection{Participants: Current Study}

One hundred and fifty-six students attending 45 different Canadian junior/community colleges and universities were participants. From a list of 14 different disabilities/impairments, 72 participants only self-reported having a learning disability (e.g., dyslexia), 42 only self-reported having ADHD, and 42 self-reported having both LD and ADHD. Students with other disabilities were excluded from the current analyses. Table 1 provides demographic information including participants' gender, field of study, qualifications pursued, registration for disability related services, and full/part-time status.

Table 1. Demographic and Student Characteristics

\begin{tabular}{|c|c|c|c|c|c|c|c|c|}
\hline \multirow[b]{2}{*}{ Demographics and Student Characteristics } & \multicolumn{2}{|c|}{ LD } & \multicolumn{2}{|c|}{ ADHD } & \multicolumn{2}{|c|}{ ADHD \& LD } & \multicolumn{2}{|c|}{ Total } \\
\hline & $n$ & $\%$ & $n$ & $\%$ & $n$ & $\%$ & $n$ & $\%$ \\
\hline \multicolumn{9}{|l|}{ Gender } \\
\hline Female & 44 & $61 \%$ & 25 & $60 \%$ & 27 & $64 \%$ & 96 & $62 \%$ \\
\hline Male & 28 & $39 \%$ & 17 & $40 \%$ & 15 & $36 \%$ & 60 & $38 \%$ \\
\hline \multicolumn{9}{|l|}{ Student Status } \\
\hline Full-time & 65 & $92 \%$ & 38 & $90 \%$ & 39 & $95 \%$ & 142 & $92 \%$ \\
\hline Part-time & 6 & $8 \%$ & 4 & $10 \%$ & 2 & $5 \%$ & 12 & $8 \%$ \\
\hline \multicolumn{9}{|l|}{ Registered for Disability Services } \\
\hline Yes & 69 & $96 \%$ & 37 & $88 \%$ & 42 & $100 \%$ & 148 & $95 \%$ \\
\hline No & 3 & $4 \%$ & 5 & $12 \%$ & 0 & $0 \%$ & 8 & $5 \%$ \\
\hline \multicolumn{9}{|l|}{ Field of Study } \\
\hline Social sciences & 22 & $31 \%$ & 12 & $29 \%$ & 16 & $38 \%$ & 50 & $32 \%$ \\
\hline Professional programs & 17 & $24 \%$ & 9 & $21 \%$ & 9 & $21 \%$ & 35 & $22 \%$ \\
\hline Science and engineering & 12 & $17 \%$ & 7 & $17 \%$ & 4 & $10 \%$ & 23 & $15 \%$ \\
\hline Business & 5 & $7 \%$ & 7 & $17 \%$ & 6 & $14 \%$ & 18 & $12 \%$ \\
\hline Arts and humanities & 8 & $11 \%$ & 5 & $12 \%$ & 4 & $10 \%$ & 17 & $11 \%$ \\
\hline Career/technical programs & 4 & $6 \%$ & 1 & $2 \%$ & 1 & $2 \%$ & 6 & $4 \%$ \\
\hline Computer and information technology & 2 & $3 \%$ & 1 & $2 \%$ & 2 & $5 \%$ & 5 & $3 \%$ \\
\hline Other & 2 & $3 \%$ & 0 & $0 \%$ & 0 & $0 \%$ & 2 & $1 \%$ \\
\hline \multicolumn{9}{|l|}{ Qualifications Pursued } \\
\hline College certificate/diploma & 30 & $42 \%$ & 22 & $52 \%$ & 17 & $41 \%$ & 69 & $45 \%$ \\
\hline Bachelor's degree & 34 & $47 \%$ & 14 & $33 \%$ & 15 & $37 \%$ & 63 & $41 \%$ \\
\hline Master's degree & 6 & $8 \%$ & 1 & $2 \%$ & 5 & $12 \%$ & 12 & $8 \%$ \\
\hline Other & 2 & $3 \%$ & 5 & $12 \%$ & 4 & $10 \%$ & 11 & $7 \%$ \\
\hline
\end{tabular}

Note: 2 students did not report their student status, and 1 student did not indicate the qualification they were pursuing. 
Statistical analyses were carried out to ensure that group differences on the variables of interest are not attributed to differences in demographic characteristics. Results from a Chi-Square analysis indicated no significant group differences for gender (96 female, 60 male). Since $95 \%$ of participants reported being registered for campus disability related services, statistical analyses could not be performed to examine group differences. Results from Analyses of Variance (ANOVA) revealed no significant group differences in (1) age ( $n=156, M=25, S D=5.29, M d n=23),(2)$ percent of program completed at the time of testing ( $n=133, M=53 \%, S D=26.10 \%, M d n=52 \%)$, (3) years of maternal education $(n=152, M=13.94, S D=3.92)$, and (4) years of paternal education $(n=148, M=13.24, S D=$ 3.78).

Results from a Chi-square analysis shows that self-reported grades differed significantly among the three groups, while most students reported being a "B student" (see Table 2). Examination of the adjusted standard residuals shows that significantly more students with LD than expected reported being a "B student" and significantly fewer than expected reported being a "C Student". Conversely, for students with ADHD, significantly more students than expected reported being a "C student" and significantly fewer than expected reported being a "B student".

Table 2. Self-Reported Grade among the Groups

\begin{tabular}{|c|c|c|c|c|c|c|c|c|}
\hline \multirow[b]{2}{*}{ Self-reported grade } & \multicolumn{2}{|c|}{ LD } & \multicolumn{2}{|c|}{ ADHD } & \multicolumn{2}{|c|}{ ADHD \& LD } & \multirow[b]{2}{*}{$\chi^{2}$} & \multirow[b]{2}{*}{$p$} \\
\hline & $n$ & $\%$ & $n$ & $\%$ & $n$ & $\%$ & & \\
\hline Grade & & & & & & & 14.89 & .005 \\
\hline A student & $15(.8)$ & $22 \%$ & $3(-2.3)$ & $7 \%$ & $10(1.5)$ & $28 \%$ & & \\
\hline B student & $43(2)$ & $63 \%$ & $20(-.9)$ & $49 \%$ & $16(-1.4)$ & $44 \%$ & & \\
\hline C Student & $10(-3)$ & $15 \%$ & $18(3)$ & $44 \%$ & $10(.2)$ & $28 \%$ & & \\
\hline Total & 69 & $100 \%$ & 41 & $100 \%$ & 39 & $100 \%$ & & \\
\hline
\end{tabular}

Note: 1 student with LD and 3 students with ADHD \& LD self-reported as a D or less student and were excluded from

the analysis due to violations of Chi-Square assumptions. Adjusted standard residuals are reported in parentheses.

\subsection{Measures}

\subsubsection{Demographic and School Related Questions}

Questions related to gender, age, parental education, disabilities/impairments, full-time/part-time student status, registration for campus disability related services, qualifications/credentials pursued (e.g., Bachelor's degree, college diploma), percentage of program completed, and field of study (coded using a validated coding manual: Martiniello, Budd, Tibbs, \& Ferraro, 2008) were included. For grades, students were asked to rate themselves as an A, B, C, or D or less student.

\subsubsection{College / University Experience Questionnaire (CEQ) (Fichten, Jorgensen, Havel, \& Barile, 2006; 2010)}

The CEQ examines aspects related to postsecondary education that act as facilitators or barriers to academic success. It includes two subscales which evaluate whether rated aspects made participants' studies easier or harder: Personal Situation (9 items - e.g., financial situation, having friends, level of personal motivation, study habits, previous education experiences, impact of my disability) and School Environment (14 items - e.g., level of difficulty of courses, course schedule, attitudes of professors, attitudes of students, availability of computers on campus, availability of course materials, willingness of professors to adapt courses to the student's needs, availability of disability related services at the school). Items are rated on a 6-point Likert-type scale from (1) much harder to (6) much easier. Higher scores indicate more facilitating conditions (i.e., made academic life easier) while lower scores indicate barriers (i.e., made academic life harder). The CEQ was found to have good internal consistency ( $\alpha=.74$ to .89) (Fichten et al., 2006). Scores on this measure have been related to the quality of academic supports that students with LD and ADHD report receiving (Wolforth \& Roberts, 2009). Additionally, Personal Situation and School Environment were related to academic satisfaction of students with and without disabilities and higher scores on Personal Situation were related to the academic retention of students with disabilities (Jorgensen, Fichten, \& Havel, 2011).

2.3.3 Self-Efficacy Questionnaire (SEQ) (Solberg et al., 1998)

The SEQ examines participants' confidence to successfully perform specific academic behaviors on a 10-point scale from (0) not at all confident to (9) very confident. We used two subscales: Course Self-Efficacy ( 7 items - e.g., take good class notes, write a course paper) and Social Self-Efficacy (6 items - e.g., talk to your instructors, participate in class discussion). Higher scores indicate greater self-efficacy beliefs. This measure was shown to have good internal consistency ( $\alpha=.83$ to .88$)$ for $1^{\text {st }}$ year college students and the scores were positively correlated with adjustment, academic persistence, and social integration (Gore, 2006).

\section{Results}

Analysis of variance (ANOVA), Chi square analyses (as reported above), and Pearson correlations were used to analyze the data. 
Results in Table 3 show significant group differences on two of the four scales: CEQ Personal Situation, $F(2,152)=$ $9.84, p<.001, \eta^{2}=.115$, and Course Self-Efficacy $F(2,152)=4.15, p=.018, \eta^{2}=.052$. Post hoc analysis (Tukey HSD) revealed that students with LD reported significantly more facilitating personal situations than students in the other two groups who did not differ from each other. Additionally, the Tukey HSD test revealed that students with LD had significantly higher Course Self-Efficacy than those with ADHD \& LD; scores of those with ADHD were not significantly different from the two other groups. Comparison of scores on CEQ School Environment and Social Self-Efficacy revealed no significant differences.

Table 3. Means, Standard Deviations, and F Scores for ANOVAs among the Groups

\begin{tabular}{|c|c|c|c|c|}
\hline Variable & $M(S D)$ & $F$ & $\eta 2$ & $\begin{array}{l}\text { Tukey HSD } \\
\end{array}$ \\
\hline Personal Situation & & $9.843^{* * *}$ & .115 & LD > ADHD ${ }^{* *}$, LD \& ADHD ${ }^{* * * *}$ \\
\hline LD & $4.19(0.83)$ & & & \\
\hline ADHD & $3.55(0.72)$ & & & \\
\hline ADHD \& LD & $3.60(1.03)$ & & & \\
\hline School Environment & & 0.560 & .007 & \\
\hline LD & $4.13(0.85)$ & & & \\
\hline ADHD & $3.99(0.81)$ & & & \\
\hline ADHD \& LD & $3.98(0.92)$ & & & \\
\hline Course Self-Efficacy & & $4.149^{* *}$ & .052 & $\mathrm{LD}>\mathrm{LD} \& \mathrm{ADHD}^{* *}$ \\
\hline LD & $6.20(1.64)$ & & & \\
\hline ADHD & $5.94(1.43)$ & & & \\
\hline ADHD \& LD & $5.28(1.88)$ & & & \\
\hline Social Self-Efficacy & & 1.312 & .017 & \\
\hline LD & $6.79(1.76)$ & & & \\
\hline ADHD & $6.53(1.74)$ & & & \\
\hline ADHD \& LD & $6.25(1.66)$ & & & \\
\hline
\end{tabular}

\subsection{CEQ Personal Situation Items}

Individual scale items were compared to examine the source of differences on the Personal Situation scale. Significant differences among the groups were found for (1) level of personal motivation $F(2,152)=4.99, p=.008, \eta 2=.062$, (2) study habits $F(2,151)=16.14, p<.001, \eta 2=.176$, (3) previous education experience $F(2,145)=3.89, p=0.023, \eta 2$ $=.051$, and (4) impact of one's disability $F(2,148)=4.23, p=.016, \eta 2=.054$. As shown in Figure 1, post hoc analyses (Tukey HSD) show that students with LD had significantly more facilitating previous educational experiences, personal motivation, and study habits, and that the impact of their disability was less debilitating than that of students who had ADHD or ADHD \& LD. Scores on the following items were not significantly different among the groups: having

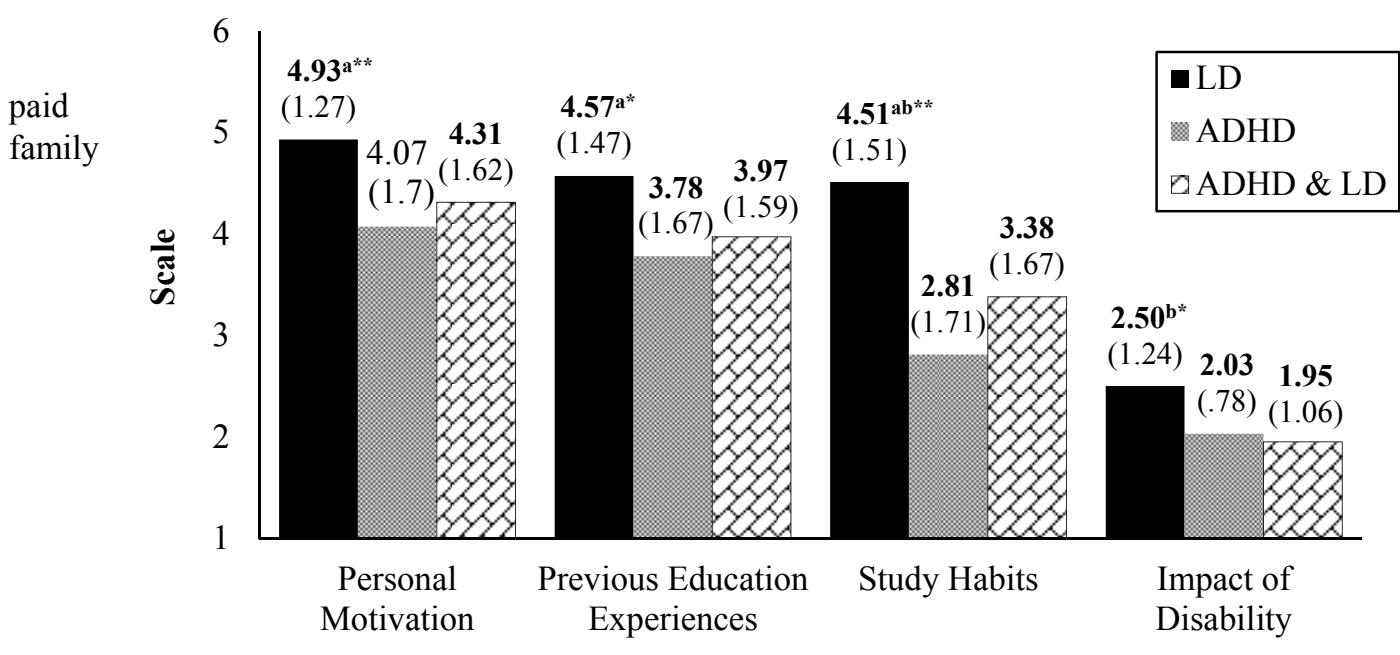

friends,

financial situation, having employment, situation, and health.

Figure 1. Personal Situation Items - Means, SD, and Tukey HSD Comparisons among the Groups

Note: $\mathrm{a}=\mathrm{LD}>\mathrm{ADHD}, \mathrm{b}=\mathrm{LD}>\mathrm{ADHD} \& \mathrm{LD} .{ }^{*} p<.05,{ }^{* *} p<.01$ 


\subsection{Course Self-Efficacy Items}

Here too, we examined individual scale items to examine the source of differences on the Course Self-Efficacy scale. Among scale items, significant group differences were found for (1) doing well on exams $F(2,152)=3.64, p=.029, \eta 2$ $=.046$, (2) efficient time management $F(2,152)=14.65, p<001, \eta 2=.162$, (3) keeping up to date with schoolwork $F(2,152)=8.97, p<.001, \eta 2=.106$, and (4) understanding textbooks $F(2,152)=4.99, p=.008, \eta 2=.062$. Tukey HSD post hoc analyses in Figure 2 show that students with LD were significantly more confident in being able to do well on exams, manage their time effectively, and keep up-to-date with school work than students who had ADHD or ADHD \& LD. The single exception to this pattern was on understanding one's textbooks, where students with ADHD had significantly greater confidence than those with ADHD \& LD. Scores on the following items did not differ significantly among the groups: taking good class notes, researching a term paper, and writing a course paper.

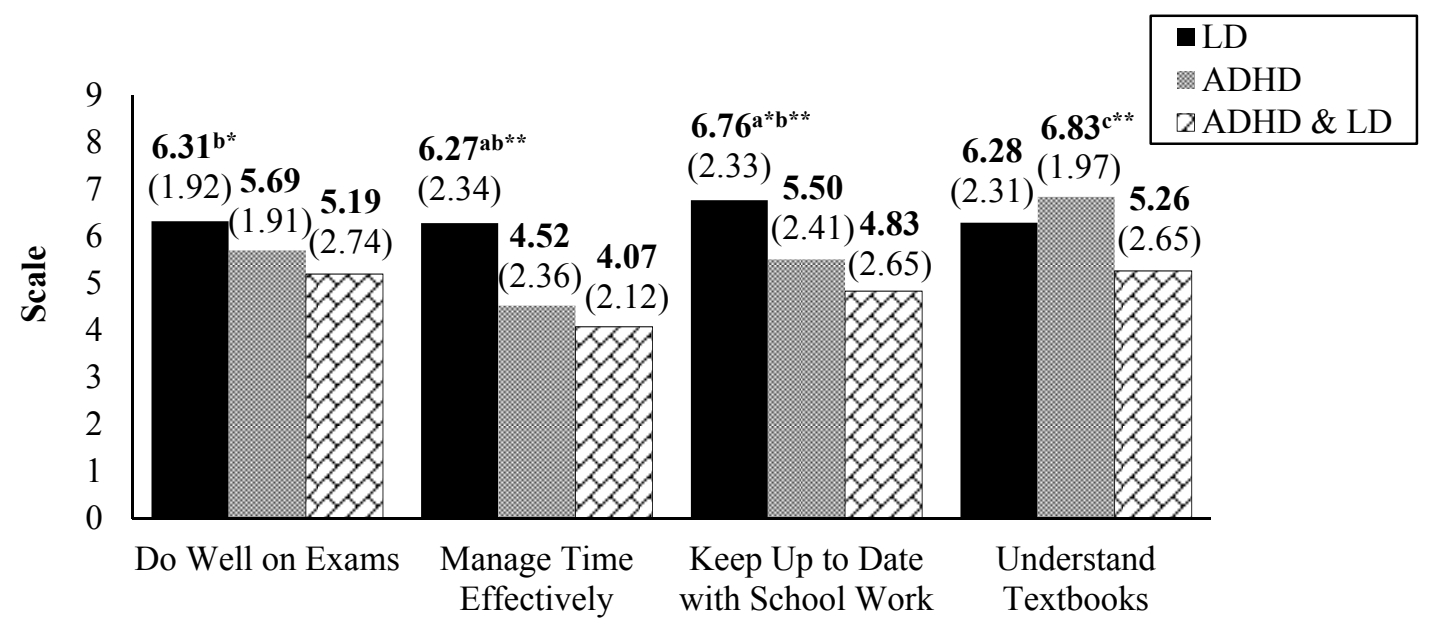

Figure 2. Course Self-Efficacy Items - Means, SD, and Tukey HSD Comparisons among the Groups

Note: $\mathrm{a}=\mathrm{LD}>\mathrm{ADHD}, \mathrm{b}=\mathrm{LD}>\mathrm{ADHD} \& \mathrm{LD}, \mathrm{c}=\mathrm{ADHD}>\mathrm{LD} \& \mathrm{ADHD} .{ }^{*} p<.05,{ }^{* *} p<.01$

\subsection{Relationships among Variables}

Correlational analyses were conducted to examine the relationships among variables for students with LD and for students with ADHD (see Table 4). Because the goal was to ascertain possible areas where there are differences, coefficients for students with ADHD \& LD are not presented. Results show that for both groups, higher scores on Course Self-Efficacy are related to higher grades, more facilitating CEQ Personal Situations, and higher ratings of Social Self-Efficacy. Additionally, for students with LD, higher parental education was related to higher grades and more facilitating CEQ Personal Situations, and higher ratings of Course Self-Efficacy was related to younger age. For students with ADHD, more facilitating SEQ Personal Situations was related to younger age.

Table 4. Correlations of Variables for Students with either LD or ADHD

\begin{tabular}{lcccccccc}
\hline Variables & 1 & 2 & 3 & 4 & 5 & 6 & 7 & 8 \\
\hline 1. Grade & - & .201 & -.086 & $.275^{*}$ & .045 & $.322^{* *}$ & $.313^{* *}$ & .009 \\
2. Personal Situation & .181 & - & $.338^{* *}$ & $.477^{* *}$ & $.362^{* *}$ & $.307^{*}$ & $.260^{*}$ & -.217 \\
3. School Environment & .195 & $.333^{*}$ & - & .188 & $.324^{* *}$ & .010 & .004 & -.127 \\
4. Course Self-Efficacy & $.439^{* *}$ & $.370^{*}$ & .267 & - & $.511^{* *}$ & .215 & .060 & $-.361^{* *}$ \\
5. Social Self-Efficacy & .303 & .199 & $.412^{* *}$ & $.414^{* *}$ & - & .124 & .050 & -.218 \\
6. Mother's education & .056 & .255 & .071 & -.093 & -.172 & - & $.673^{* *}$ & -.088 \\
7. Father's education & -.172 & .307 & .048 & -.075 & -.080 & $.559^{* *}$ & - & -.084 \\
8. Age & .230 & $-.397^{* *}$ & -.278 & .063 & .068 & $-.394^{*}$ & $-.349^{*}$ & - \\
\hline
\end{tabular}

Note: Students with LD are above the diagonal and students with ADHD are below the diagonal.

\section{Discussion}

$* p<.05, * * p<.01$

\subsection{Question 1: Similarities and Differences among Groups}

We sought to determine similarities and differences on grades, self-efficacy, and obstacles and facilitators to academic success among students with LD, ADHD, and comorbid ADHD and LD. Overall, we found that students with LD tended to have the most favorable scores. 


\subsubsection{Grades}

The majority of students in the study reported themselves as a "B Student", however, significantly more students with ADHD than expected reported themselves as a "C Student" in comparison to the other groups. This finding is consistent with previous research showing that college students with ADHD tend to have low grades (Advokat et al., 2011; Weyandt et al., 2013).

\subsubsection{Course Self-Efficacy}

Postsecondary students with LD tend to have lower academic self-efficacy beliefs than their peers without LD (Hen \& Goroshit, 2014); these are generally rooted in past achievement, difficulties, and personal history (Lackaye \& Margalit, 2006). In contrast, research on self-efficacy in postsecondary students with ADHD is lacking. Overall, we found that students with LD were significantly more confident in their ability to carry out course-related tasks than students with comorbid ADHD and LD, while students with ADHD were not different from either group. Our findings regarding students with LD are inconsistent with previous literature, as their moderately high self-confidence scores resemble those of nondisabled populations (Solberg et al., 1998).

We examined individual scale items to shed light on specific topics where students' level of confidence differed. Students with comorbid ADHD and LD had the lowest confidence ratings regarding doing well on their exams, a finding similar to that reported by Lewandowski, Gathje, Lovett and Gordon (2013), who found that college students with ADHD (20\% with comorbid LD) had low confidence in being able to perform well on exams. Additionally, students with LD were more confident than those with ADHD and the comorbid group on being able to manage their time effectively as well as on keeping up-to-date with their school work, a finding consistent with Reaser et al. (2007). Low confidence on these items for students with ADHD (with or without LD comorbidity) may reflect executive functioning deficits (Gray, Fettes, Woltering, Mawjee, \& Tannock, 2015; Wolf, 2001). The only context where students with ADHD had more confidence than students with comorbid ADHD and LD was related to ability to understand one's textbooks. While both individuals with LD and with ADHD tend to have reading comprehension difficulties, the etiologies of these are different (Samuelsson, Lundberg, \& Herkner, 2004). Thus, having comorbid ADHD and LD may make reading comprehension even more difficult.

\subsubsection{Personal Situation}

We compared the groups to examine aspects of students' personal situations that made their studies easier (facilitators) or harder (barriers). Overall, students with learning disabilities' personal situations made their studies easier than students with ADHD and the comorbid group. As with course self-efficacy, we examined individual scale items to shed light on the specific aspects in which students' ratings differed. Students with ADHD reported that their level of personal motivation made their studies harder in comparison to those with LD. This finding differs from Reaser et al. (2007), who found no significant differences in motivation between the groups. Similarly, students with ADHD indicated less favorable previous education experiences than did students with LD, a finding that may be related to inappropriate supports given to children who only have ADHD in secondary school (Tsagris \& Muirhead, 2012).

Students with ADHD and with comorbid ADHD and LD felt that their study habits made their academic studies harder than that reported by students with LD. The literature shows that students with LD often have to develop special study methods and use compensatory strategies (Ruban, McCoach, McGuire, \& Reis, 2003). While the actual study habits of students with ADHD do not differ from those without disabilities (Reaser et al., 2007), they have been shown to report poorer study skills overall (Weyandt et al., 2013). Thus, students with ADHD and comorbid ADHD and LD may benefit from receiving extra support to help improve their study skills and study habits. Students with comorbid ADHD and LD were more likely to report that the impact of their disability made their academic studies harder than did students with LD, while those with ADHD did not differ from either group. This finding suggests that having ADHD in addition to having LD is perceived by students as being more intrusive than having LD alone.

\subsection{Question 2: Relationships between Grades and Other Variables}

Because our goal was to ascertain possible areas of differences between students with LD and with ADHD, we examined correlations among variables for these two groups. Results show that for both groups, higher confidence in one's ability to carry out course-related tasks was related to more facilitating personal situations, higher social self-efficacy, and higher self-reported grades, a finding consistent with Butler (2011).

They key differences between the groups were found for parental education and students' age. For students with LD, higher parental education was related to higher self-reported grades and more facilitating personal situations. This was not the case for students with ADHD. Additionally, while younger age was associated with higher course self-efficacy for students with LD, this was not true for students with ADHD, although younger age was associated with more facilitating personal situations for these students. 


\subsection{Limitations and Future Directions}

Sampling in our investigation was neither random nor fully representative of the populations studied. Additionally, students who choose to participate in research studies have been found to have better grades than those who do not volunteer (Jorgensen \& Fichten, 2007; Woosley, 2005). The use of e-mail discussion lists as a main form of recruitment may also have led to a biased sample. Additionally, since the recruitment strategy included asking disability service providers to help recruit participants, the majority of students had registered for disability related services at their institution. This resulted in under-representation of students who did not register for campus disability related services. Another limitation is the use of self-report. In addition, while data indicate that most students with ADHD take stimulant medication (Advokat et al., 2011), we did not ask participations about their medication use.

The limitations suggest the direction for future research. For example, to avoid the under-representation of students who do not register for disability related services, we suggest that freshman surveys be carried out, preferably at registration, when these are part of the enrollment process. In addition, GPAs from students' transcripts should be used. Moreover, it would be interesting to examine the relationship between students' high school and college grades.

The literature suggests that $2 \%$ to $8 \%$ of college students self-report clinically significant symptoms associated with ADHD (DuPaul, Weyandt, O'Dell, \& Varejao, 2009). Future research should examine academic performance in relation to the number and/or severity of such symptoms, use of/perceived usefulness of study strategies, executive functioning deficits, along with medication use. In addition, students who have ADHD often have comorbid disabilities other than LD, including anxiety (Goniu \& Moreno, 2013) and depression (Blase et al., 2009). Thus, it would be of interest to examine the contribution of these comorbidities to students' academic performance.

\subsection{Practical Implications}

Our results highlight the need to eliminate the common practice of classifying students with LD and with ADHD as one unified group. While we found similarities between postsecondary students with LD and with ADHD, our findings also shed light on important differences; students with ADHD (with or without LD comorbidity) had lower grades and experienced more barriers to academic success and lower self-efficacy for executive functioning related academic tasks. Combining these groups may lead to confounding results in research and produce inappropriate academic interventions and accommodations.

Because there is a substantial literature on interventions and accommodations that can assist students with LD (Gregg, 2012), here we focus on postsecondary students with ADHD. These students are likely to benefit from academic interventions and accommodations targeted at improving executive functioning. When students transition to postsecondary education, those who are better able to self-regulate (e.g., manage time effectively, organize tasks) are more likely to have better grades (Huie, Winsler, \& Kitsantas, 2014). Consequently, poorer grades may be the product of poor executive functioning and not lack of ability (Huie et al., 2014). These needed skills may not be targeted in typical interventions and accommodations provided to students with ADHD before they enter postsecondary education. For instance, the most frequent accommodations/supports given to high school students with ADHD, found in an 8-year follow-up of the multi-site multimodal treatment study of ADHD, were unrelated to improving executive functioning or self-regulation (Murray et al., 2014). Taken together, our findings highlight the need for self-regulation and executive functioning interventions for students with ADHD in college/university as well as in high school.

Colleges and universities can help better respond to the needs of students with ADHD by sponsoring workshops and programs aimed at improving executive functioning and self-regulation skills (e.g., time management, organization, prioritization, planning). Additionally, postsecondary schools can implement ADHD coaching programs (e.g., cognitive-behavioral therapy with psychoeducational techniques) as it has been found to improve students' study and learning strategies, self-esteem, and satisfaction with school (Prevatt \& Yelland, 2015).

\subsection{Conclusions}

Examination of the experiences of college students with ADHD, LD, and comorbid ADHD and LD showed that students with ADHD had worse grades, personal situations, and course self-efficacy than students with LD. In addition, comorbid ADHD and LD sometimes led to worse outcomes than did LD or ADHD alone, suggesting that it is important to distinguish among the three groups of students: those with ADHD, LD, and comorbid ADHD and LD. Future research needs to focus on the reasons why students with ADHD and comorbid ADHD and LD experience difficulty in college and on what could be done to help them. A promising avenue relates to executive functioning and self-regulation.

\section{Acknowledgments}

This study was funded by the Social Sciences and Humanities Research Council of Canada (SSHRC). We are grateful for their support. We would like to thank our partner groups which made this research possible: AQEIPS - Association 
Québécoise des étudiants ayant des incapacités au postsecondaire and NEADS - National Educational Association of Disabled Students. We would also like to thank Mai Nhu Nguyen and Laura King for their dedication to this project and support.

\section{References}

Advokat, C., Lane, S. M., \& Luo, C. (2011). College students with and without ADHD: Comparison of self-report of medication usage, study habits, and academic achievement. Journal of Attention Disorders, 15, 656-666. http://dx.doi.org/10.1177/1087054710371168

American College Health Association (2013). American College Health Association-National College Health Assessment II: Candian reference group executive summary spring 2013. Hanover, MD: American College Health Association.

American Psychiatric Association. (2013). Diagnostic and statistical manual of mental disorders (5th ed.). Arlington, VA: American Psychiatric Publishing.

Barkley, R. A., Fischer, M., Smallish, L., \& Fletcher, K. (2006). Young adult outcome of hyperactive children: Adaptive functioning in major life activities. Journal of the American Academy of Child and Adolescent Psychiatry, 45, 192-202. http://dx.doi.org/10.1097/01.chi.0000189134.97436.e2

Bental, B., \& Tirosh, E. (2007). The relationship between attention, executive functions and reading domain abilities in attention deficit hyperactivity disorder and reading disorder: A comparative study. Journal of Child Psychology and Psychiatry, 48, 455-463. http://dx.doi.org/10.1111/j.1469-7610.2006.01710.x

Bizier, C., Till, M., \& Nicholls, G. (2014). Learning disabilities among Canadians aged 15 years and older, 2012. Statistics Canada Catalogue no. 89-654-X. Retrieved from http://www5.statcan.gc.ca/olc-cel/olc.action?objId=89-654-X2014003\&objType=46\&lang=en\&limit=0

Blase, S. L., Gilbert, A. N., Anastopoulos, A. D., Costello, E. J., Hoyle, R. H., Swartzwelder, H. H., \& Rabiner, D. L. (2009). Self-reported ADHD and adjustment in college: Cross-sectional and longitudinal findings. Journal of Attention Disorders, 13, 297-309. http://dx.doi.org/10.1177/1087054709334446

Butler, A. L. (2011). Secondary transition experiences: Analyzing perceptions, academic self-efficacy, academic adjustment and GPA for college students with learning disabilities pursuing postsecondary education (Doctoral dissertation). Retrieved from ProQuest Dissertations and Theses database. (UMI No. 3461499)

DeDonno, M. A., \& Fagan, J. F. (2013). The influence of family attributes on students' academic self-concept. North American Journal of Psychology, 15(1), 49-62.

DuPaul, G. J., Gormley, M. J., \& Laracy, S. D. (2013). Comorbidity of LD and ADHD: Implications of DSM-5 for assessment and treatment. Journal of Learning Disabilities, 46, 43-51. http://dx.doi.org/10.1177/0022219412464351

DuPaul, G. J., Weyandt, L. L., O'Dell, S. M., \& Varejao, M. (2009). College students with ADHD: Current status and future directions. Journal of Attention Disorders, 13, 234-250. http://dx.doi.org/10.1177/1087054709340650.

Fichten, C. S., Jorgensen, S., Havel, A., \& Barile, M. (2006). College students with disabilities: Their future and success. Retrieved from ERIC database. (ED491585)

Fichten, C. S., Jorgensen, S., Havel, A., \& Barile, M. (2010). College / University Experience Questionnaire (CEQ). Retrieved from http://www.adaptech.org/pubs/CollegeUniversityExperienceQuestionnaire2010.doc

Fichten, C. S., Nguyen, M. N., Amsel, R., Jorgensen, S., Budd, J., Jorgensen, M., \& Barile, M. (2014). How well does the theory of planned behavior predict graduation among college and university students with disabilities? Social Psychology of Education, 17, 657-685. http://dx.doi.org/10.1007/s11218-014-9272-8

Goniu, N., \& Moreno, M. (2013). Increased risk for anxiety among college students with ADHD [Poster abstract]. Journal of Adolescent Health, 52, S81. http://dx.doi.org/10.1016/j.jadohealth.2012.10.189

Gore, P. A. (2006). Academic self-efficacy as a predictor of college outcomes: Two incremental validity studies. Journal of Career Assessment, 92, 92-115. http://dx.doi.org/10.1177/1069072705281367

Gray, S. A., Fettes, P., Woltering, S., Mawjee, K., \& Tannock, R. (2015). Symptom manifestation and impairments in college students with ADHD. Journal of Learning Disabilities. Advance online publication. http://dx.doi.org/10.1177/0022219415576523

Gregg, N. (2007). Underserved and unprepared: Postsecondary learning disabilities. Learning Disabilities Research \& Practice, 22, 219-228. http://dx.doi.org/10.1111/j.1540-5826.2007.00250.x

Gregg, N. (2012). Increasing access to learning for the adult basic education learner with learning disabilities: 
Evidence-based accommodation research. Journal of Learning Disabilities, 45, 47-63. http://dx.doi.org/10.1177/0022219411426855

Harrison, A. G., \& Holmes, A. (2012). Easier said than done: Operationalizing the diagnosis of learning disability for use at the postsecondary level in Canada. Canadian Journal of School Psychology, 27, 12-34. http://dx.doi.org/10.1177/0829573512437021

Harrison, A. G., Larochette, A. C., \& Nichols, E. (2007). Students with learning disabilities in postsecondary education: Selected initial characteristics. Exceptionality Education Canada, 17(2), 135-154. Retrieved from http://eric.ed.gov/?id=EJ773907

Hen, M., \& Goroshit, M. (2014). Academic procrastination, emotional intelligence, academic self-efficacy, and GPA: A comparison between students with and without learning disabilities. Journal of Learning Disabilities, 47, 116-124. http://dx.doi.org/10.1177/0022219412439325

Huie, F. C., Winsler, A., \& Kitsantas, A. (2014). Employment and first-year college achievement: The role of self-regulation and motivation. Journal of Education and Work, 27, 110-135. http://dx.doi.org/10.1080/13639080.2012.718746

Jorgensen, S., \& Fichten, C. S. (2007). Linking grades and college graduates' perceptions of obstacles and facilitators: A cautionary tale. Retrieved from ERIC database. (ED498249)

Jorgensen, S., Fichten, C. S., \& Havel, A. (2009). Academic success of graduates with and without disabilities - A comparative study of university entrance scores. Pédagogie Collégiale, 22(5), 26-29. Retrieved from http://www.aqpc.qc.ca/

Jorgensen, S., Fichten, C. S., \& Havel, A. (2011). College satisfaction and academic success. Retrieved from ERIC database. (ED522996)

Katz, L. J., Brown, F. C., Roth, R. M., \& Beers, S. R. (2011). Processing speed and working memory performance in those with both ADHD and a reading disorder compared with those with ADHD alone. Archives of Clinical Neuropsychology, 26, 425-433. http://dx.doi.org/10.1093/arclin/acr026

Kent, K. M., Pelham, W. E., Jr., Molina, B. S. G., Sibley, M. H., Waschbusch, D. A., Yu, J., \& Karch, K. M. (2011). The academic experience of male high school students with ADHD. Journal of Abnormal Child Psychology, 39, 451-462. http://dx.doi.org/10.1007/s10802-010-9472-4

Lackaye, T. D., \& Margalit, M. (2006). Comparisons of achievement, effort, and self-perceptions among students with learning disabilities and their peers from different achievement groups. Journal of Learning Disabilities, 39, 432-446. http://dx.doi.org/10.1177/00222194060390050501

Lewandowski, L. J., Lovett, B. J., Codding, R. S., \& Gordon, M. (2008). Symptoms of ADHD and academic concerns in college students with and without ADHD diagnoses. Journal of Attention Disorders, 12, 156-161. http://dx.doi.org/10.1177/1087054707310882

Lewandowski, L., Gathje, R. A., Lovett, B. J., \& Gordon, M. (2013). Test-taking skills in college students with and without ADHD. Journal of Psychoeducational Assessment, 31, 41-52. http://dx.doi.org/10.1177/0734282912446304

Martiniello, N., Budd, J., Tibbs, A., \& Ferraro, V. (2008). Disciplines coding manual for college and university studies. Retrieved http://adaptech.org/sites/default/files/abDisciplineCodingManualforCollegeandUniversityStudies.doc

Marzocchi, G. M., Oosterlaan, J., Zuddas A., Cavolina, P., Geurts, H., Redigolo, D., ... Sergeant, J. A. (2008). Contrasting deficits on executive functions between ADHD and reading disabled children. Journal of Child Psychology and Psychiatry, 49, 543-552. http://dx.doi.org/10.1111/j.1469-7610.2007.01859.x

McCloy, U., \& DeClou, L. (2013). Disability in Ontario: Postsecondary education participation rates, student experience and labour market outcomes. Toronto, Ontario: Higher Education Quality Council of Ontario. Retrieved from http://www.heqco.ca/SiteCollectionDocuments/At\%20Issue\%20-\%20Disability\%20in\%20ON_ENG.pdf

Mortimore, T., \& Crozier, W. R. (2006). Dyslexia and difficulties with study skills in higher education. Studies in Higher Education, 31, 235-251. http://dx.doi.org/10.1080/03075070600572173

Murray, D. W., Molina, B. S. G., Glew, K., Houck, P., Greiner, A., Fong, D., \& Jensen, P. S. (2014). Prevalence and characteristics of school services for high school students with attention-deficit/hyperactivity disorder. School Mental Health: A Multidisciplinary Research and Practice Journal, 6, 264-278. http://dx.doi.org/ 10.1007/s12310-014-9128-6 
National Center for Education Statistics. (2011). Students with disabilities at degree-granting postsecondary institutions: First look. Washington, DC: US Department of Education. Retrieved from http://oeraccess.merlot.org/_media/documents/Students\%20with\%20Disabilities.pdf

Parker, D. R., \& Banerjee, M. (2007). Leveling the digital playing field: Assessing the learning technology needs of college-bound students with LD and/or ADHD. Assessment for Effective Intervention, 33, 5-14. http://dx.doi.org/10.1177/15345084070330010201.

Prevatt, F., \& Yelland, S. (2015). An empirical evaluation of ADHD coaching in college students. Journal of Attention Disorders, 19, 666-677. http://dx.doi.org/10.1177/1087054713480036

Prevatt, F., \& Young, J. L. (2014). Recognizing and treating attention-deficit/hyperactivity disorder in college students. Journal of College Student Psychotherapy, 28, 182-200. http://dx.doi.org/10.1080/87568225.2014.914825

Rath, K. A., \& Royer, J. M. (2002). The nature and effectiveness of learning disability services for college students. Educational Psychology Review, 14, 353-381. http://dx.doi.org/10.1023/A:1020694510935.

Raue, K., \& Lewis, L. (2011). Students with disabilities at degree-granting postsecondary institutions (NCES Publication No. 2011018). Retrieved from National Center for Education Statistics website: http://nces.ed.gov/pubs2011/2011018.pdf

Reaser, A., Prevatt, F., Petscher, Y., \& Proctor, B. (2007). The learning and study strategies of college students with ADHD. Psychology in the Schools, 44, 627-638. http://dx.doi.org/10.1002/pits.20252

Richardson, M., Abraham, C., \& Bond, R. (2012). Psychological correlates of university students' academic performance: A systematic review and meta-analysis. Psychological Bulletin, 138, 353-387. http://dx.doi.org/10.1037/a0026838

Ruban, L. M., McCoach, D. B., McGuire, J. M., \& Reis, S. M. (2003). The differential impact of academic self-regulatory methods on academic achievement among university students with and without learning disabilities. Journal of Learning Disabilities, 36, 270-286. http://dx.doi.org/10.1177/002221940303600306

Samuelsson, S., Lundberg, I., \& Herkner, B. (2004). ADHD and reading disability in male adults: Is there a connection? Journal of Learning Disabilities, 37, 155-168. http://dx.doi.org/10.1177/00222194040370020601

Solberg, V.S., Gusavac, N., Hamann, T., Felch, J., Johnson, J., Lamborn, S., \& Torres, J. (1998). The adaptive success identity plan (ASIP): A career intervention for college students. The Career Development Quarterly, 47, 48-95. http://dx.doi.org/10.1002/j.2161-0045.1998.tb00728.x

Tarver, J., Daley, D., \& Sayal, K. (2014). Attention-deficit hyperactivity disorder (ADHD): An updated review of the essential facts. Child: Care, Health and Development, 40, 762-774. http://dx.doi.org/10.1111/cch.12139

Tsagris, D., Muirhead, B. (2012). Evaluating postsecondary supports for Ontario students with learning disabilities. Toronto, Ontario: Higher Education Quality Council of Ontario Retrieved from http://www.heqco.ca/SiteCollectionDocuments/EvaluatingPSESupportsForStudentsWithLearningDisabilities.pdf

Wagner, M., Newman, L., Cameto, R., Garza, N., \& Levine, P. (2005). After high school: A first look at the postschool experiences of youth with disabilities: A report from the National Longitudinal Transition Study-2 (NLTS2). U.S. Department of Education. http://www.nlts2.org/reports/2005_04/nlts2_report_2005_04_execsum.pdf

Weyandt., L., DuPaul, G. J., Verdi, G., Rossi, J. S., Swentosky, A. J., Vilardo, B. S., \& Carson, K. S. (2013). The performance of college students with and without ADHD: Neuropsychological, academic, and psychosocial functioning. Journal of Psychopathology and Behavioral Assessment, 35, 421-435. http://dx.doi.org/10.1007/s10862-013-9351-8

Wolf, L. E. (2001). College students with ADHD and other hidden disabilities. Annals of the New York Academy of Sciences, 931, 385-395. http://dx.doi.org/10.1111/j.1749-6632.2001.tb05792.x

Wolforth, J., \& Roberts, E. (2009). The situation of students with learning disabilities or attention deficit disorder in CEGEPS in the province of Quebec: Are they a group that demonstrates a legitimate need for funding and services? Montreal, QC: McGill University.

Woosley, A. S. (2005). Survey response and its relationship to educational outcomes among first-year college students. Journal of College Student Retention: Research, Theory \& Practice, 6, 413-423. http://dx.doi.org/10.2190/61B3-KTKC-WCRE-RH1N

\section{(cc) $\mathrm{Er}$}

This work is licensed under a Creative Commons Attribution 3.0 License. 